\title{
PROBLEMS OF IMPLEMENTATION OF INFORMATION TECHNOLOGY IN THE HOUSING SECTOR IN RUSSIA
}

\author{
Sergey A. KIRSANOV ${ }^{1}$, Yevgeny N. SAFONOV ${ }^{2}$ \\ ${ }^{1,2}$ Russian State University for the Humanities (Domodedovo Branch), Russian Federation \\ ksaimr@mail.ru \\ ensafonov_55@mail.ru
}

\begin{abstract}
The considerable problems in the provision of a transparent and clear system of settlement between the enterprises supplying housing and utilities services and the owners of flat buildings include the insufficient provision of metering devices, the absence of a system collecting and analysing this information and the data of the current balances of utilities, as well as the absence of a common data base of the residents. To solve the above-mentioned problems, it is necessary to implement strict normative requirements related to the application of the metering devices and arrange the uniform municipal bases of information resources, which would include the automated information collection, payment servicing of utility consumers in a single window, the control over the unsanctioned utility consumption, the data exchange with the branch state automated systems and other measures.
\end{abstract}

Keywords: Information technologies, innovative technologies, housing and utilities sector modernisation, uniform information resource of housing, utilities and amenities.

\section{INTRODUCTION}

The development of housing, utilities and amenities (further - the HUA) is included into the issues of local importance, which directly affects the quality of life of most residents of municipal units. At present, in the conditions of the annual growth of tariffs the HUA is a source of constant social tension. But the municipal units do not have either sufficient finance to solve these problems or real opportunities to duly control and regulate the sphere (Bulavinov, 2013).

The HUA tariff policy is developed by the Government of the RF in cooperation with the federal agencies of executive authority - the Federal Tariff Service of the RF, the Ministry of Regional Development, the Ministry of Industry and Energy, the Ministry of Economic Development and Trade etc., as well as the regional and municipal agencies of executive authority in the tariff regulation - the Regional Energy Commissions, the regional and municipal committees, departments, and prices and tariffs regulating services.

The main problem is that in the process of implementation of socially important reforms, including in the HUA, the federal agencies of executive authority have to use the information contained in the isolated and diverse information resources. The specified information resources have no uniform rules of data formation and no uniform infrastructure of data collection in the electronic form; the analogous information in different databases may considerably differ. It affects the efficiency of implemented laws and federal programmes (Kazanskaya, 2006). 


\section{GENERAL REGULATIONS}

Pursuant to the national programme of Russia - the Information Society (2011-2020), the transfer to the modern information society is related to the development of information technologies and systems based on the service oriented architecture, the development of the networks of access to the information, the formation of digital content, and the development of convenient services for the citizens (The Decree of the Government of the Russian Federation, 2014). The main tasks and goals of the programme include the arrangement and development of electronic services in the housing and utilities sector. The directions of the housing and utilities sector development are specified in the Decree of the Government of the RF dated February 2, 2010 No. 102-r concerning the Validation of the Concept of the Federal Target Program Integrated Program of Housing and Utilities Sector Modernization and Reforming for 2010-2020 (The Decree of the Government of the Russian Federation as of February 2, 2010). The presence of a uniform municipal base of information resources in the HUA is among the main requirements to the participation in the federal target programme. The arrangement of the uniform centres for the information processing (multifunctional centres) in the housing and utilities sector is the necessary precondition for the data exchange throughout the power vertical, which would provide the order and convenience of citizen serving (Patudin \& Yurtaikin, 2010).

The considerable problems in the provision of a transparent and clear system of settlement between the enterprises supplying the housing and utilities services (further - the HUS) and the owners of flat buildings include the insufficient provision of metering devices, the absence of a system collecting and analysing this information and the data of the current balances of utilities, as well as the absence of a common data base of the residents. To solve the above-mentioned problems, it is necessary to implement strict normative requirements to the application of the metering devices and arrange the uniform municipal bases of information resources, which would include the automated information collection, payment servicing of utility consumers in a single window, the control over the unsanctioned utility consumption, the data exchange with the branch state automated systems and other measures (The Decree of the Government of the Russian Federation as of February 2, 2010).

The modern information technologies allow monitoring the state of the HUA facilities, accounting the utility consumption, and providing the adequate interaction between their suppliers and consumers. The situation operative control based on the information technologies is necessary for the optimal budgeting, the investment project formation and implementation, the account of real current payments, the work performance planning and control, and the development of the branch regulatory and legal framework. The wide implementation of the information technologies will allow the citizens to be the end consumers of the HUS, controlling the utility consumption and optimising the expenses (The Automated Information System of Housing and Utilities Amenities, 2006). 
The list of tasks to be performed with the use of the information systems in the HUA (Saak, Pakhomov \& Tyushnyakov, 2012):

- dispatching control acceleration;

- information processing of the technical state of housing stock in a given territory ;

- remote management of HUA facilities;

- situation modelling;

- utility accounting and payment calculation;

- improvement of quality of work with the population;

- municipal authority information servicing;

- data exchange web-services;

- budget money saving.

The management information technologies used in the housing and utilities sector include (The Automated Information System of Housing and Utilities Amenities, 2006):

- the automated dispatch control systems - a set of programs and hardware intended for the automation of the real time management of geographically dispersed processes and living facilities of the municipal and housing facilities;

- the automated systems of payments for the accrual, accounting, and processing of housing and utility services;

- the automated account systems of water consumption;

- the support of the personal accounts updated in respect of the information on the structure of residents and number of supplied services split by the service providers;

- the account of provided service amount and nomenclature, and the calculation of their cost;

- the calculation of services on the basis of the metering device readings;

- the account of privileged categories of citizens in accordance with the federal and municipal legislation both for the decrease in the payment for the housing and utilities services and for the targeted compensation payments;

- the notification of home owners about the current charges and debts to the service providers;

- the acceptance of the payments for the housing and utilities services upon receipt and the money acceptance registration with the help of the fiscal data recorder;

- the calculation of penalties for late payments for the housing and utilities services;

- the account of subsidies for the poor;

- the reassessment of the amounts accrued for the housing and utilities services upon a change in the reference data.

The information system (further - the GIS HUA) being in process of arrangement in Russia shall become the information system of new generation, which would provide the completeness and accuracy of the information on the 
state of affairs in the housing and utilities sector. On the one hand, the GIS HUA will provide the service of collection, processing, and storage at the database of the information on the housing service provision and work on the flat building management, overhaul, and measures of citizens' social support. On the other hand, the GIS HUA implementation in form of the Internet portal will become a centralised resource of updated and consistent information, with the help of which home owners, companies operating in the housing and utilities sector, as well as the state and local authorities will be able to get the detailed information on the state of housing and utilities sector in the regions and in the country as a whole. For the users' convenience, the system will be integrated into the Electronic Government (Bulavinov, 2013).

At present, the pilot projects of GIS HUA are launched in five constituent entities of the Russian Federation (Belgorod, Kursk, Penza, and Tula regions, as well as the Udmurt Republic); in each a local system operator is appointed.

The specialised resource HUA has begun operating in the testing mode in Moscow. According to AwStats data, the number of unique visitors of the resource exceeds 500 people a day.

The GIS HUA will allow the dwellers to calculate the service costs and pay for them on their own; it will also give an opportunity to address any problem, to send an application for the work performance and complaints of the negligent utility providers. The GIS will allow obtaining the information on the utility providers, the readings of the individual and communal meters, etc. The arrangement of GIS HUA will allow arranging a uniform housing and utility information resource for the efficient arrangement of electric power, heat, gas, and water supply, as well as wastewater disposal all over the Russian Federation.

\section{THE PRECONDITIONS OF THE INFORMATION TECHNOLOGY IMPLEMENTATION IN THE ACTIVITY OF HUA ENTERPRISES}

The imperfection of current red-tape formal mechanisms of pricing management in the housing and utilities sector is one of the main causes of uncontrolled growth of the tariffs for the housing and utilities services. The absence of an opportunity to promptly collect and analyse the data on the daily business processes in the HUA discourages the rational economic behaviour of all subjects of the market and administrative relations in the housing and utilities sector (starting with the utilities providing organisations and finishing with the end consumers).

As in any other badly managed social and economic system, the aggressive and insufficiently controlled organised subjects get the "bonuses" and excess profits here, while the most unprotected and disorganized subjects - the end consumers - suffer and pay for it.

The efficient transformation of relations in the HUA presupposes taking into account the lessons of its reformations in the countries with different levels of social and economic development. The analysis of reformation experience in Eastern Europe shows that the first stage of reformation of the housing and utilities services is bringing them into order, including the arrangement of 
interaction among the market participants, bringing the settlements into order, and control over the provided service quality (Balikoev, 2009).

The uniform information space of the regulatory agencies, businesses, and consumers shall have the vertical integrated hierarchical structure in accordance with the structure of the current authority - the federal, regional, and municipal levels. Each hierarchy level shall have its relative information centre - the federal, regional, and municipal information centres. The managerial decisions made by the regulatory agencies shall be based on the information streams from the efficient informational and communicational business infrastructure. In this connection, it is necessary to facilitate the innovative technology implementation in the economic activity of the HUA subjects.

It is necessary to facilitate such business projects as the implementation of ERP-system (Enterprise Resource Planning System), CRM-system, the automatic process control systems (APCS), the automated measuring and information systems for electric power fiscal accounting, consumer notification centres, payment and service systems, information portals, etc.

The implementation of the above-mentioned innovative technologies in the activity of the housing and utilities companies will provide an opportunity to form the operative and accurate information on the HUA state, which will allow the efficient managerial decision making, in particular, in the regulation of the HUS cost.

The innovative technology implementation both in the power vertical and the housing and utilities company horizontal will allow considerably decreasing the growth rate of housing and utilities service prices. Thus, at present, when there is no operative control by the federal authorities over the actions of the regional and municipal authorities, there are multiple opportunities to include the excess profit into the tariff and increase the nominal prime cost of housing and utilities services, which leads to uncontrolled tariff growth.

In case of implementation of the innovative and analytical systems of management of the HUA only in the authorities without the innovative technology implementation in the business structures, the situation will be characterised by the strict state control over the housing and utilities service pricing, but only in the part of determination and account of the officially provided documentation of the housing and utilities agencies. In this case, the analytical system data will not contain the objective information on the real expenditures. The control over the HUS price growth will be limited only to the regulation of the housing and utility companies' profit norm. Such one-sided regulation already now results in considerable distortions in the data provided and taken into account in the calculation by the regional regulating authorities for tariff determination.

On the other hand, the absence of the mechanisms of efficient state control based on the analytical systems does not prevent some housing and utility companies from implementing the innovative technology in order to cut the prime cost of provided services. But in this case only the housing and utility companies have the accurate and operative data on the current business processes forming the financial flows as well as the utility distribution and consumption optimisation. In this case, the authorities are not aware of the improvements. It allows the 
companies after the pay-back period to get the excess profit from the innovative technology implementation for an uncontrolled period of time and substantiate their tariffs with the outdated norms of energy loss.

Thus, a considerable increase in the HUA management efficiency (Kruglik, 2008), formation of a fair balanced cost of HUS, and considerable improvement in their quality can be achieved only with the sufficient and necessary penetration of suggested innovative technologies both in the power vertical and in the housing and utility companies horizontal.

Nowadays, the role of information technologies in the social and economic development of the regions of Russia has qualitatively changed, because their implementation allows not only changing the rules of interaction of the state agencies with the companies and citizens, but also improving the efficiency of company internal communications as well as the interaction and information transfer among the employees inside an organisation. It is impossible to arrange the rational and elaborate management by the state structures of any level without the structures and integrated software and hardware adapted to certain business processes. In this connection, the information technologies become an integral tool for the implementation of the task of the Russian economy transition to the innovative development, its diversification, and improvement of its global competing ability.

The analysis of the implemented automated economic and information system in the HUA agencies and the business processes structure shows that the developers of the current economic and information system have not taken into account a number of factors, which allow optimising the business processes. It is necessary to optimise the business process structure, which will allow cutting the number of HUA employees and the utility expenditures.

\section{RESULTS}

The uniform information space of the regulatory agencies, businesses, and consumers shall have the vertical integrated hierarchical structure in accordance with the structure of the current authority - the federal, regional, and municipal levels. Each hierarchy level shall have its relative information centre - the federal, regional, and municipal information centres. The managerial decisions made by the regulatory agencies shall be based on the information streams from the efficient informational and communicational business infrastructure. In this connection, it is necessary to facilitate the innovative technology implementation in the economic activity of the HUA subjects.

The present day conditions allow two variants of automated information and communication system of measurement, accounting and calculation of utility consumption in the residential and other buildings. The first variant: the transfer by a fiscal metering operator of the data from the individual and communal meters to the settlement centres of the managing companies, which calculate the payments in compliance with the current rules and draw the payment documents, including the annual correction calculations for each type of resource and each personal account. The second variant: the complete calculation in compliance with 
the current rules and drawing of the payment documents, including the annual correction calculations for all types of resources, by a fiscal meter operator, which sends the payment documents in the electronic form and their hard copy to the managing companies.

The widening of the system functions by means of installation of the devices regulating the heat, water, and electric power for the purposes to cut the utility consumption also provides the wider opportunities for the housing and utility engineer system monitoring and utility consumption automated management.

Nowadays, such systems are widely used in the countries of European Union, North America, and South-eastern Asia. In Russia, the installation of such systems accounting the water and heat in each flat is launched by the concern Techem under the brand Data (registered in the State Register of meters under No. 41943-09) and the general name Techem Smart System (Data TSS).

With the use of such systems, the population seriously advantages getting a device for the regulation, objective measurement, account, and calculation of utilities as well as the transparency and fairness of payments for the utility consumption. The state benefits from the energy consumption decrease and the social order in the community.

The payback period of the installation of the regulated automated heat supply stations in the buildings, instead of inefficient central heat supply stations, with the installation in each flat of regulating devices and the automated devices metering the water, heat, gas, and electric power is 2-3 years. They guarantee the energy consumption decrease by each end consumer by an average of 20-30\%, provide the fair payment for the utilities by each consumer, and will motivate each consumer to decrease the energy consumption. The energy saving by the end consumers results in a considerable decrease - up to 2-3 times - compared to the saved energy of fuel consumption in the process of energy production and transportation.

According to the experts' estimation, the increase of efficiency of end energy use in Russia may save $154 \mathrm{mln}$. TOE (tons of oil equivalent): in the buildings $68 \mathrm{mln}$. TOE (in the residential buildings - 53; in the service sphere buildings 15). In the industry (excluding the FEC), the saving may reach $41 \mathrm{mln}$. TOE, which exceeds the annual energy consumption in such countries as Poland, the Netherlands or Turkey. Therefore, the work on the decrease of energy consumption by the end consumers in the residential buildings and other building with the use of the ICT shall become the primary and the most important chain in the provision of energy consumption decrease in the whole network of utility supply.

\section{CONCLUSION}

The practical absence of integrity and system character as well as the real use of the cutting-edge technologies in the new construction and overhaul all over Russia is an important problem for the present day development and modernisation of the utilities sector, which results in the waste of billions of ruble and conservation of outdated engineering solutions. 
Thus, the foreign experience of many years shows the huge efficiency of the information and communication technology use in the housing and utilities systems providing the population life, including the energy saving and ecological friendliness.

It is necessary to arrange the socially oriented and feasible institutions in the utilities sector, which allow the formation of the objective conditions for the real development of service provision system. At the same time, the integral obligation, mission, and the "dominating competence of the state" require the implementation of a number of functions, including the institutional ones, i.e. the state shall participate in the arrangement and strengthening of the social and economic institutions.

\section{REFERENCES}

The Decree of the Government of the Russian Federation dated April 15, (2014). No. 313 Concerning the National Program of the Russian Federation the Information Society (20112020). Retrieved from: https://www.consultant.ru/document/cons_doc_LAW_106767/4b6b1ec 3d9a61a8204d8fdc520469db8e0daa367/

The Decree of the Government of the Russian Federation dated February 2, (2010). No. 102-r Concerning the Validation of the Concept of the Federal Target Program Integrated Program of Housing and utilities amenities Modernization and Reforming for 2010-2020. Retrieved from http://www.rg.ru/2010/02/16/jkx-site-dok.html

The budget versus actual report. (2015). The Federal Treasury of the RF official site. Retrieved from http://www.roskazna.ru/ispolnenie-byudzhetov/

The automated information system Housing and Utilities Amenities. (2006). Retrieved from http://www.insoft.ru/insoft/products/products_ais_JKH/Opisanie_AIS_JKH.pdf

Balikoev, A. A. (2009). Correction of the Reformation Course of Housing and Utilities Services of Present Day Russia: Paradigm, Rules, Resources, Tools, Regional Component. (Doctoral dissertation summary, Adygei State University). p. 59.

Bulavinov, V. E. (2013). Concerning the Arrangement of a State Information System of Housing and Utilities Sector. Municipal Administration Practice, 3, 84-89.

Volchaninov, L., \& Ilin, S. (2008). The Crisis will Promote More Active Implementation of DPC Optimization Technologies. Retrieved from http://www.cnews.ru/reviews/free/infrastructure2008/ articles/cod.shtml

Kazanskaya, A. Yu. (2006). Municipal Units Social and Economic State Integrated Assessment Method Development. The electronic academic periodicals Researched in Russia, 43, 426-442. Retrieved from http://zhurnal.ape.relarn.ru/articles/2006/043.pdf

Kirsanov, S. A., Safonov, E. N., \& Sidorenko, E. A. (2010). Managing an Apartment Building: Organizational, Legal and Economic Principles: a guide. - Moscow: Integratsya, p. 292.

Kirsanov, S. A., \& Safonov, E. N. (2012). Problems and Innovations in Providing Information on the Management of Apartment Buildings. Journal of Economic Integration, 7(51), 65-73.

Kirsanov, S. A., \& Safonov, E. N. (2013). Improvement of Public Housing Policy in Russia through an Example of Saint Petersburg / The XI International scientific conference Management and Engineering - 13, June 23-26, 2013, Sozopol, Bulgaria. p. 556.

Kruglik, S. I. (2008). Methodological Framework of Managing Russian Cities Housing and Utilities Sector (Doctoral dissertation summary, Saint Petersburg University) p. 39.

Makarenya, T. A., \& Stash, S. V. (2012). The Problems of Water Supply Enterprises Regulation and Modernization (on the example of Rostov-on-Don). The national interests, priorities, and safety, 35(176), 25-33.

Patudin, V. M., \& Yurtaikin, E. A. (2010). Concerning the Arrangement of Information and Analytical Center for Information Processing in the HUA of Region in a Single Window Retrieved from http://sm-center.ru/mobile/Articles/Details.aspx?id=226 
Saak, A. E., Pakhomov, E. V., Tyushnyakov, V. N. (2012). Management Information Technologies: Course-book for universities (2nd ed.). Saint Petersburg, p. 320.

Sinelnikov, T. T. (2008). The Development of Authorities and Business Interaction Mechanisms: the Foreign Experience and Russian Practice. The Southern Federal University Izvestiya. Technical sciences, 1(78), 151 .

Tyushnyakov, V. N. (2011). State and Municipal Service Quality Improvement on the Basis of Multifunctional Centers. The Southern Federal University Izvestiya. Technical sciences, 11(124), 224-232.

Jim Fink, P. E. (2007). Data Center Humidification Strategies. Retrieved from http://www.slideshare.net/datacenters/apc-application-note-128

\section{AUTHORS' BIOGRAPHIES}

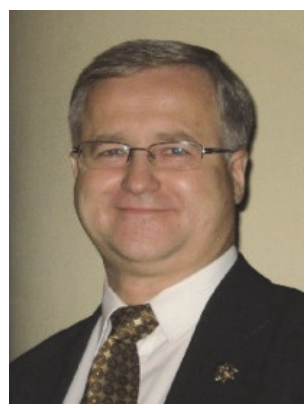

Prof. Kirsanov Sergey, Candidate of Economics, Full Member of the Russian Academy of Sciences, Branch Professor of "Domodedovo" Russian State University for the Humanities, Russia.

Kirsanov Sergey received a second degree in State and Municipal Management from St. Petersburg State University.

Kirsanov S. A. has for a long time been working in the urban economy of St. Petersburg and has been three times elected as a Deputy of the Municipal Council Kolpino. He is the Head of the Department of State and Municipal Management in St. Petersburg Institute of Humanities. The research interests: administrative and municipal reform, provision of public and municipal services, efficiency of local government, modernisation of housing and utilities services, quality of housing and utilities services. He is the author and co-author of over 250 publications and books on housing and local government.

$\mathrm{He}$ is a member of the competition committee for expert review of candidates for the vacant positions of the state civil service of Leningrad region in the executive authority of Leningrad region and a similar committee of the Accounts Chamber of Leningrad Region and a member of the Public Council on Housing Policy and Housing of Saint-Petersburg and Leningrad Region and a member of the Board of Trustees of Non-Profit Partnership Sojkinskaja Shrine. He was awarded the medal in memory of the $300^{\text {th }}$ anniversary of St. Petersburg, and he is a knight of the sign of Alexander Nevsky for Fatherland and Proceedings.

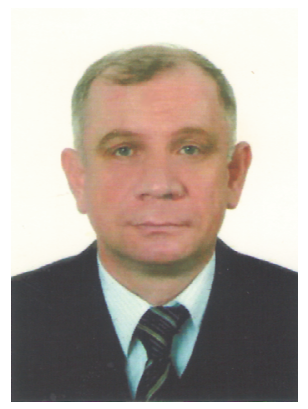

Safonov Evgeny graduated from Moscow Institute of Chemical Engineering in 1977. In 1987, he became the Doctor of Philosophy in Economics and in 2007 - the Doctor of Economic Sciences. In 2009, he took the position of Professor at the Department of Public Administration. Since 2012, he has been a Member of the Russian Academy of Natural Sciences.

Since 1999 to present, he holds the position of the Director of SEI HPE Russian State University for the Humanities in Domodedovo.

The research interests: innovation strategy, commercialisation of the results of intellectual activity, modernisation of housing and utilities services, innovation in the provision of housing and utilities services. He is the author and co-author of over 150 publications and books on economics and management in the sectors of economy.

He has been the Deputy Member of Domodedovo City Council since 2006 and was the Chairman of the Public Chamber of the city district Domodedovo in 2005-2012. 